\title{
POST-START-UP OVERLAP AND DISATTENTIVENESS IN TALK IN A GARRWA COMMUNITY
}

\author{
Rod Gardner, Griffith University \\ Rod Gardner is an Associate Professor at Griffith University. His major field of \\ research is in conversation analysis, in particular of response tokens and second \\ language conversation. He is author of When Listeners Talk (John Benjamins, \\ 2001), and co-editor (with Johannes Wagner) of Second Language Conversations \\ (Continuum, 2004). \\ Correspondence to Rod Gardner: r.gardner@griffith.edu.au \\ Ilana Mushin, University of Queensland \\ Ilana Mushin is a lecturer in Linguistics at the University of Queensland. Her major \\ fields of research include discourse analysis, language change and Australian Ab- \\ original languages, especially Garrwa. She is author of Evidentiality and Epistem- \\ ological Stance (John Benjamins, 2001). \\ Correspondence to Ilana Mushin: i.mushin@uq.edu.au
}

Overlap in conversation is a well-established area of conversation analysis research (e.g. Jefferson 1983; Schegloff 2000) which can reveal how participants orient to transition relevance places. This paper presents an analysis of overlap in the mixed (Garrwa, Kriol and English) language conversations of two indigenous Australian women as part of a larger study of turn-taking practices in indigenous conversations. Walsh (Walsh 1995) made some observations about Aboriginal conversational style, for example that they may enter a conversation without attending to the talk of others. His observational claims are empirically examined here in the context of our data.

We find that the overlapping talk in our data follows many patterns similar to English speakers' talk, including transition space overlap (cf. Jefferson 1983) and simultaneous starts. The most important difference we found was overlap onset occurring shortly after the closure of the transition space, reflecting disattendance by speakers to the content, but not the timing, of each other's talk. Overall, however, we find that the turn-taking of these two women is overwhelmingly orderly, and deviations from orderliness can mostly be accounted for by their orientation to points of possible completion and rules of turn-taking as described by Sacks, Schegloff and Jefferson (1974). 


\section{INTRODUCTION}

A question of potential interest in the study of the ways people take turns in conversation is the extent to which practices are similar across different languages and cultures. Despite claims that some cultures, such as East European and Mediterranean, have a greater tolerance for simultaneous, or overlapping, talk than North American or British English speakers (e.g. Maschler 2003; Schegloff 2000), or that some others such as many Asian cultures have a lower tolerance (e.g. Hayashi 1988; Tanaka 1999), there has been little data-driven research to support such claims. Most research on overlapping talk has been on English, and, to a lesser extent, on some other major European languages and Japanese. There has been very little on small minority languages around the world, and nothing on Australian indigenous languages.

In the indigenous Australian context, Walsh (Walsh 1995: 219-224) identified a particular conversational style for Murrinh-Patha, a language spoken in the Daly River region in the Northern Territory, which he stated as being non-dyadic and continuous with a tolerance for long periods of silence. By this he means that speakers start and stop speaking without attending to the progress of the talk of others in the context of gatherings of people around a camp - what he terms 'broadcast talk', which is addressed to all co-present. The consequence of this would be a high incidence of overlapping talk. The idea of long periods of silence appears to capture another aspect of conversational style in this group, which is more likely to result in the opposite phenomenon, namely a lower incidence of overlapping talk. Anecdotally other Australianists have recognised this style as being widespread.

These claims have been based on ethnographic observations. There are no detailed studies using close transcriptions of conversational data. In this paper we present an analysis of such materials. Garrwa is spoken in the south-western Gulf of Carpentaria region between Borroloola and Doomadgee. The data are from four audio-recorded conversations in Borroloola (40 minutes closely transcribed) between two elderly Garrwa women (Ellen and Tina). These women are amongst the last remaining first language speakers (probably fewer than 100), but in daily communication they mix languages between Garrwa, Kriol and Aboriginal English. The conversations occurred prior to or during breaks in work sessions in which they were working as linguistic consultants with the second author. They largely involve storytelling on current affairs of the community and assessment of people and events. The second author was mostly absent during these conversations, but is present some of the time. Implications of her presence on the patterns of turn-taking observed here will be discussed later. Further video-recorded conversations 
involving three other Garrwa women, which have as yet not been closely transcribed, appear to support the analysis we are presenting here.

In these 40 minutes, there were 81 occurrences of overlapping talk. We found many similarities to what has been reported in previous conversation analytic work on overlap, particularly Jefferson (Jefferson 1983), in terms of timing and placement of overlap onset. There were, however, also some differences. Overlap occurred at a somewhat lower frequency than is typical for Anglo-Australian talk, though not markedly so. Long periods of silence occurred only occasionally in these conversations (contra Walsh 1995: 220), but we found large numbers of short to medium length inter-turn silences of up to about two to three seconds, at a higher rate than has been observed for Anglo-Australian conversations (Gardner 1995: 44). Most notably, over 10 per cent of the overlaps that did occur were of a type not described by Jefferson (Jefferson 1983) for North American and British talk. In these instances a speaker starts up shortly after another speaker has begun talking. We call these 'post-start-up' overlap, illustrated in (1) below. These usually occurred when speakers were being disattentive to each other's talk - what can be called a tolerance for disalignment. In some, but not all, cases a third speaker (usually the second author) was present so that the talk involved two participants independently addressing the third party. This is reminiscent of Walsh's broadcast talk and is the main feature of their talk we describe here: ${ }^{1}$

\section{(1) 9.10 .03 .5}

1 .

2. TD: $\underline{A}: \mathrm{N}^{\prime}(0.4)$-ehhh

3. ER: and l'll check- dere na [(ba-)]

4. TD: [l b]i' lang=

5. TD: = $\quad$ MEE $:$ ding dere yesterday $\uparrow$ ?

$\mathrm{ft} \quad \mathrm{I}$ went to a meeting there yesterday?

$6 . \quad(0.8)$

7. TD: $->$ Ea:::rly dey bin [git me.]

$f t \quad$ They came to get me early
8. ER: $->\quad\left[>\mid b^{\prime} n\right.$ a]s' im; $<\uparrow$ 个ALLOE.:; $\mathrm{ft} \quad$ I said 'hello' to him

9. ER: $\quad>$ I bi' see t'b'la; $<\underline{e}$ :re nah ou'side. $\mathrm{ft} \quad$ I saw those two outside here

$10 . \quad(0.4)$

11. ER: ((sn[iff))

12. TD: [Uh huhn,

13. (0.3) 
In this extract, where only Ellen and Tina ${ }^{2}$ are present, both are broadly talking on the same topic, namely the effort Ellen had taken to find Tina (unsuccessfully). However there is a misalignment in terms of the relevance of each participant's response to the other's turn: Ellen is telling about her own efforts to find Tina while Tina is saying where she had been (at a meeting). This is a symptom of disattentiveness, which seems to be the source of the overlap in line 12. Ellen's entry at line 12 comes well after Tina's turn starts, but too early for this to be an anticipation of Tina's turn ending.

\section{OVERLAP AND TURN TAKING}

As this paper is centrally about how turn taking behaviour reflects the social actions being performed, we first present some general comments on turn taking and overlap from the conversation analysis literature, before focussing on post-start-up overlaps and their relevance to the actions of the participants.

According to Sacks, Schegloff and Jefferson's (Sacks, Schegloff and Jefferson 1974) well-known explication of basic turn-taking systematics, based on North American ordinary conversation, turn taking is orderly. The following three observations they made are highly relevant to our study of overlap:

Overwhelmingly one party talks at a time;

Occurrences of more than one speaker at a time are common but brief;

Transitions (from one turn to the next) with no gap and no overlap are common. ([...] slight gap or slight overlap [...] make up the vast majority of transitions). (Sacks, Schegloff and Jefferson 1974: 700-701).

This orderliness occurs, they say, because speakers orient to beginning their turns at points at which an utterance is grammatically complete, and construct them with turn constructional units (TCUs). A TCU is the minimal unit that can constitute a complete turn. It can be a word, a phrase, a clause or a sentence. The end of a TCU - what SSJ called a transitional relevance place (TRP) - is a point at which a new speaker is sanctioned to start talking. SSJ also found three ways in which speakers take the floor: either they are selected by the prior speaker or they select themselves to speak (in that order of preference). If neither of these occurs, the current speaker may continue (Sacks, Schegloff and Jefferson 1974: 704). 
SSJ claim that these rules apply to all ordinary conversations (not, though, to institutional talk, such as in classrooms, courtrooms or media interviews), and as such the rules are context-free. However, as conversations occur in real life situations, speakers need to be sensitive to actual contexts, and with every utterance make judgements about when to start. Of course, such judgements may result in miscues for one reason or another, and one consequence of such miscues is overlapping talk.

A significant contribution to the overlap literature was Jefferson's. She 'noticed that not all overlap was a matter of "people just not listening to each other"' (Jefferson 1983: 11). Instead she found, similarly to Schegloff (Schegloff 2000) a number of years later, a 'pervasive orderliness... in occurrences of overlap' (Jefferson 1983: 11), and she described three distinctive major types of overlap onset. The first of these was transitional overlap. This occurs at or close to TRPs, sometimes as a result of a minor miscue of speaker entry. The second is recognitional overlap, which occurs well before a TRP, when the incoming speaker has heard enough of the current turn to be able to identify what the current speaker is in the course of saying. The third type is progressional overlap, which occurs when 'a problem arises in its progression towards completion and/or adequacy' (Jefferson 1983: 12), and is manifested in the form of hitches.

It may be noted that Jefferson does not include interruption as one of her overlap types. One reason is that if the analyst orients the analysis to how the participants treat the overlap, then it is rare indeed to find instances of overlap being treated overtly as interruption. In fact one finds a great toleration of overlapping talk in the materials she (and we) examined, as overwhelmingly such talk is treated as 'business-as-usual'. Schegloff is drawn to the conclusion that the notion of 'interruption' is equivocal, and that overlap as interruption is 'a practical matter of its "complainability" for those parties [in the conversation], at that moment, with those overlapping utterances, and so forth' (Schegloff 2002: 301). However, given the practical difficulties for an analyst in establishing which instances of incoming talk overlapping current speaker are 'complainables', he concludes that 'overlap' - a practice amenable to analysis of positions within talk - and 'interruption' - a vernacular term - are 'perhaps irreconcilable alternatives', and 'there is very likely no formula for converting one to the other' (Schegloff 2002: 314).

This work by Schegloff and Jefferson used materials from North American and British conversations. Thus there is a question as to whether what they explicate is applicable to talk in other cultures. Some classic ethnographic papers have claimed that talk in non-European cultures is often oriented to different conversational and turntaking norms. For example Reisman (Reisman 1974) reported a much greater tolerance for simultaneous talk in Antiguan market places, and this is echoed in Walsh's (Walsh 
1995: 219-224) observations of Murrinh-Patha conversation. Specifically on overlapping talk, Reisman on Antiguan Creole says, 'there is no regular requirement for two or more voices not to be going at the same time... no sense of interruption... or need to stop if someone speaks' (Reisman 1974: 133). Challenging these claims, Sidnell, using a CA approach, found that turn taking in the Creole in Guyana (closely related to Antiguan Creole) was 'identical in all relevant respects to that described for American English conversations' (Sidnell 2001: 1266), and that 'the orderliness of conversation [...] is grounded in a species-specific adaptation to the contingencies of human social intercourse' (Sidnell 2001: 1263). Similar conclusions are reached by Moerman (Moerman 1988: 182-5) for Thai, using a combination of ethnographic and CA methods.

So if turn-taking is a species-specific adaptation, as Sidnell suggests, what is it that Walsh is noticing with his broadcast talk and non-attendance to other speakers' talk in Murrinh-Patha communities? In our data we found that the majority of overlaps could be described in terms of the types identified in Jefferson (Jefferson 1983). We did however find a type which was not described, but which did occur relatively frequently in our data, and which may be a display of the kind of conversation style described by Walsh. This is the post-start-up overlap, an example of which was presented in (1) above.

Jefferson (Jefferson 1983: 21) describes a phenomenon with some structural similarities to our post-start-up overlaps. This occurs when a speaker reaches a TRP and then leaves a little gap of silence. A recipient responds in that gap, but the prior speaker then continues with further talk a fraction of a second after this response begins, resulting in overlap. Jefferson argues that there is a tiny space after completion of a TCU, which she calls a 'blind spot', in which a recipient may be 'blind' to whether prior speaker is going to continue. Sometimes the recipient starts up in this tiny space even though there is no gap of silence, having projected completion and non-continuation by the prior speaker. Our post-start-up overlaps are different in that the incoming speaker has heard two or more beats of talk before beginning to speak, which means that he or she is well past this blind spot.

Some post-start-up overlaps occur in three party conversations, where two speakers are addressing the third, but independently. This is reminiscent of what Egbert (Egbert 1997) has discussed as schisming. This occurs when a conversation involving at least four participants splits into two (or more) conversations. As SSJ say, schisms can occur 'when at least four parties are present, since then there are enough parties for two conversations' (Sacks, Schegloff and Jefferson 1974: 713). What appears to be happening in some of the three-party post-start-up overlaps is that an incipient schism is happening, but a full schism cannot occur as there are not enough participants for a full schism. 
In the next section we examine the nature of these post-start-up overlaps in detail, how they relate to other types of conversational behaviour described for other groups, and how they relate to Walsh's observations on Murrinh-Patha conversation style.

\section{DISATTENTIVENESS AND OVERLAP}

In this section we focus on a type of overlap which was not described in Jefferson (Jefferson 1983), but which occurs relatively frequently in our data, at just over 10 per cent of all overlaps. These are post-start-up overlaps, which occur when one speaker begins speaking a little after another has started. These differ from Jefferson's blind spots in unmarked next position overlap because the overlapping speaker comes in after the transition space has closed. They differ from recognitional overlap in that the incoming speaker begins to speak before there is any evidence as to what kind of utterance is being produced.

In the first example of post-start-up overlaps, Tina and Ellen are talking about a dance. This is part of an extended sequence concerning what happened during a ceremony at which Ellen was present, but Tina and Ilana were not:

\section{(2) 8.9.03.392}

1. ER: $\quad$ They are like a: (0.2) $\uparrow \underline{f}$ :rien' du frien'- $\uparrow$.

2. $(0.7)$

3. IM: [Mm:.]

4. TD: [Mm:.]

5. (0.9)

6. ER: Kuna:k'.hh

$\mathrm{ft}$ : name.of.dance

7. (1.6)

8. ER: [(Ah you be- $)]$

9. TD: [You're friend] to $\uparrow \underline{u}: \mathrm{s}$.

10. IM: $\mathrm{Mm}[:$.

11. ER: $[\mathrm{Mm}]$ :

12. (0.5)

13. ER?: -hhm.

14. (2.0)

15. TD: Kuna- u:m:

16. ER: ha $\uparrow$ yo: uh $=$

17. TD: =k'naki.

$\mathrm{ft}$ : name.of.dance

18. TD?: ((sniff)) 


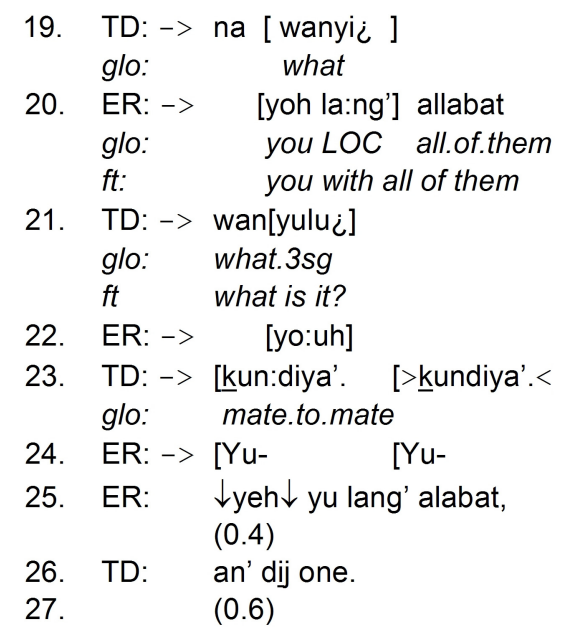

At the beginning of this extract, Tina and Ellen are both explaining to Ilana the way a certain ceremonial dance is performed. The start of this extract, They are like a friend to friend, sees Ellen explaining a part of the dance where women dance in pairs as 'friends'. In line 6 she names this way of dancing - kunaki. In the meantime in line 9, Tina mentions to Ilana that she would be considered a 'friend' to Tina and Ellen. This is minimally acknowledged by both Ilana (the intended recipient) and Ellen.

After a pause of a little over 2.5 seconds, Tina begins to repeat the name of the dance that had been proffered by Ellen. She embarks on a word search, which will simultaneously be a correction of Ellen's name for the dance. First, she begins with a repeat of Ellen's version, but stops half way through (kuna-), and then produces a hesitation marking $u m$. This is the first indication that there is trouble with this name. She then repeats the word kunaki (line 17), and in lines 19 (wanyi 'what') and 21 (wanyulu 'what is it') she appears to be questioning whether this is the right Garrwa term for this kind of dancing. In line 23 she comes up with a different word, kundiya(rra), as the correct name. We can therefore say that Tina's contributions between 15 and 23 are a unilateral word search and a correction of Ellen.

While Tina is engaged in this word search, Ellen has embarked on her own course of action. This is an example of a place where a schism might well result if there were four or more speakers (cf. Egbert 1997). She has picked up the theme of Ilana's relationship to the dancers as a friend. This may have started already in line 8 (the hearing is uncertain), but her ha you in line 16 gets the turn going, which is continued in line 20 
she says Yu langa allabat ('You with all of them'), which partially overlaps Tina's na wanyi ('what') in line 19, part of her independent word search. Perhaps because of this overlap, Ellen embarks on a repetition of yoh lang allabat, with a number of restarts: in line 22 and twice in line 24, before a full repetition in line 25. So each of them has been engaged in quite separate actions: Tina's word search and Ellen's declaration that Ilana is included in this 'friendship'. However, they are not responding to the substantive content of each other's talk. Ellen is clearly addressing Ilana $(y o u)$, whereas Tina appears to be addressing both, or even neither (her talk is not soft, and there is no evidence that she is addressing only one).

Yet whilst they are not responding to each other's actions, they are attentive to the emergence of each other's talk and to turn starts and completions. Ellen's ha you (line 16 ) is placed in an intraturn pause during the first part of Tina's word search. Note next that Ellen's first you lang allabat (line 20) does not begin until after Tina has started (i.e. Tina's first syllable na, - we have not been able to establish the meaning of this form is out in the open). However, this clearly is neither a point of possible completion, nor could Ellen have recognised what Tina is about to say. Indeed Ellen's talk is disattentive to Tina's word search, but sensitive to the start of her turn.

In the transition space after Ellen completes her TCU in line 20, Tina repeats and slightly reformulates her question in line 21 with wanyulu ('what is it'). Once again Tina manages to get one syllable in the clear (the 'wan' in wanyulu) before Ellen enters again with you: another restart - and another post-start-up overlap. The overlapping talk continues in lines 23 and 24 with Tina now announcing the correct name for the dance style. Meanwhile, Ellen makes three tries at repeating her utterance, in 22 and 24, before she finally gets it fully out in the clear at line 25. Interestingly, the repetitions of 'yu' in line 24 are timed to coincide precisely with the start of Tina's two sayings of kundiyarra, demonstrating further that while they are being disattentive to each others' topical talk, and both are in competition for the floor, they are nonetheless sensitive to transition relevance places. Ellen's acknowledgement in line 25 (yeh), is perhaps a sign that despite being focussed on her own attempts to gain the floor, she has nonetheless heard what Tina has been saying and is here acknowledging the validity of the term kundiyarra.

The examples of post-start-up overlap in (2) can perhaps be accounted for by a third party's (Ilana's) presence, which results in both Ellen and Tina simultaneously talking to Ilana on different topics, thereby disattending to each other. However overlaps of this kind did not only occur when there was a third party present. In extract (3), Ilana is not a participant (although she is audible in one place in the background). This is from a story of a fight involving Ellen's grandchildren. Ellen had been the storyteller, Tina the 
recipient. At the beginning of this extract, Ellen exhorts Tina to tell one of the fighters that she had done the wrong thing:

\section{(3) 9.10.03.298}

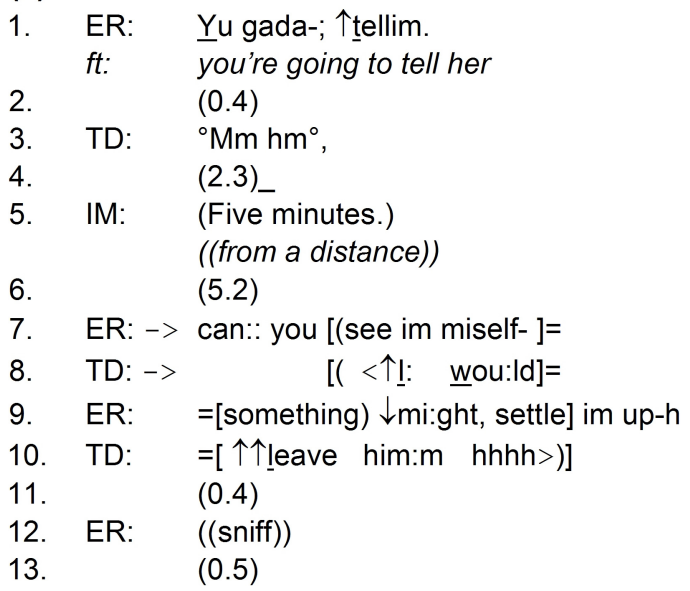

After $y u$ gada tellim in line 1, there is a very long silence of over 8 seconds (punctuated by Ilana calling out in the background). Ellen then adds something that sounds like a rhetorical question about whether the fighter can calm him-/herself down, though this is not clear. After can:: you, which is about four beats, and which is not a recognisable action at this point, Tina starts responding to Ellen's exhortation - I would leave him (i.e. she wouldn't tell him). Both finish their turns in overlap, and without any noticeable hitches or perturbations. Note that the story has already ended, so even if Tina can not know exactly what Ellen is about to say, she does know the kind of action that is relevant after a story's telling has been completed, i.e. something such as a formulation or upshot of the story - which is indeed what Ellen does. The reason she does not wait for Ellen to finish her formulation is that a response to the formulation would become a relevant next (Schegloff 1968: 1083), and adjacency to Ellen's you gada tellim would be lost. So it is Ellen's starting up that prompts Tina's overlap, and there is a sense in which a poststart-up overlap is the last opportunity to get her response done. It can also be noted that they are not being fully disattentive in this case to what each is doing, as both produce relevant next actions following the sequence from one to three, although the action each produces is disaligned from the other. 
These two extracts demonstrate the relationship between disattentive talk or disaligned actions and the incidence of post-start-up overlaps. The next extract, from a different conversation, also provides examples of post-start-up overlap in a context of disattentiveness to each other, but in this case they are engaged in a similar activity, and their actions are more aligned.

Extract (4) comes from a conversation between Tina and Ellen about another fight, this one involving Ellen's grandson and his wife. Tina had heard about, but not witnessed, the fight. At this stage in the conversation, Ilana has arrived, having been absent for Ellen's initial telling to Tina. This extract is part of Ellen and Tina's co-telling to Ilana:

(4) 20.8.03.312

1. ER: E:ê:.: 'e b'n (.) da:ba dat ng:ila wi:fe;=
glo:
he PAST fight that girl wife

ft: he fought that girl, wife

2. ER: =la im $\uparrow$ na: ¿hh=>tubala b'n< w::alkin'=

glo: $\quad$ LOC him NA 3du PAST walking

ft: $\quad$ there, those two were walking

3. ER: =fr'm $\underline{\text { h}}$ :ere nachh

glo: from here NA

$\mathrm{ft}$ : from here

4. IM: ${ }^{\circ} \mathrm{Mm}:{ }^{\circ}$.

$5 . \quad(1.2)$

6. TD: $->$ an' e ['saulted he:r. [个crady.]

7. $\quad$ ER: $->\quad[i \mathrm{~m}: \mathrm{m}$ a: $\mathrm{d}$; [e mad; ] dat

8. ER: =my: gran'son-; (0.4) an' 个im: gran'son;

glo: $\quad$ grandson and im grandson

9. ER: < țubala bin: d:rinkiman.

3du PAST drink

$\mathrm{ft}$ he's mad, he's mad. That one, my grandson, and her grandson, those two got drunk.

Ellen had been telling the story up to the point where this extract begins. In lines 1-3, mixing Garrwa and Kriol, she recounts the main event in the story: that her grandson had been fighting with his wife while walking back to the camp. In line 6, Tina takes up the telling from Ellen after a 1.2 second pause, with the upshot of the story: that he had assaulted his wife. Ellen, meanwhile, comes in with an assessment of her grandson, im mad, e mad. This occurs two syllables into Tina's turn. This is not responsive 
to the content of Tina's turn, as Ellen has not heard enough to recognise what Tina might have been saying,

After Ellen's assessment in line 7, she continues with more detail about the story. Tina's assessment at the end of line 6 ( $\mathrm{rady}$ 'crazy') comes in unmarked next position after Ellen's equivalent assessment, which indicates that Tina has been attending to Ellen during her own turn, and now responds with an agreeing assessment in overlap. So there is a lot of evidence that they are tracking each other's turns, sensitive to TRPs and turn starts. The overlap in lines 6-7 occurs because Tina and Ellen, whilst both engaged in telling the story to Ilana, are doing so independently. There has been a gap of 1.2 seconds, so this is well past a TRP. Ellen's start-up occurs on the third beat into Tina's turn, but does not address its content.

\section{CONCLUSION}

The overlap behaviour of the dyadic or triadic talk involving two Garrwa women whose conversations are reported on in this paper shows many similarities to that described for North American and British speakers. Overlaps around the transition space were by far the most common type. Simultaneous starts were also common. There were, though, few recognitional and no progressional overlaps in the data. The rate of overlap was quite low compared to Anglo-Australian conversations, but not extremely so. There were, though, a lot of mid-length inter-turn silences of up to a little over two seconds. These findings support the notion that while the mechanics of conversational turn-taking may be a feature of human sociality, there may be cultural differences with respect to what is considered 'normal' timing of turns, including a tolerance for more or less overlapping talk, tolerance for disalignment with at least one other in multi-party talk, and silence.

In our data, we found a regularly occurring type of overlap that is not described in the literature. These post-start-up overlaps occur when a speaker starts to overlap shortly after another speaker has begun a turn. The onset comes after the transition space, but before enough of the first speaker's talk has emerged for the turn to be recognisable. The onset of this type of overlap, therefore, can be said to be placed later than what Jefferson calls unmarked next position overlap, i.e. the latest point within the normal transition space, and earlier than recognitional overlap. Post-start-up overlaps often occur when the speakers are being disattentive to the content and action of each other's talk, though there is evidence that they are still being attentive and sensitive to the rhythms of the talk 
and to TRPs. Such talk was found both when they were conversing with a third person present, but also when there were only the two of them.

Post-start-up overlaps are consistent with the broadcast talk that Walsh (Walsh 1995) reported for Murrinh-Patha, in that, even in these dyadic/triadic situations, there were occasions when talk was not built to be a relevant next (Schegloff 1968). In order to test Walsh's claims further, it will be necessary to analyse talk in more public situations in which larger groups of potential speakers are present, and people come and go. It would also be interesting to compare our data, where two participants simultaneously talk to a third participant, with other conversations, to establish whether post-start-up overlaps occur more generally as a consequence of such disattentiveness.

\section{ACKNOWLEDGEMENTS}

We would like to thank the two editors of this volume and Jack Sidnell for their feedback on an earlier draft of this paper. We would also like to extend our gratitude to the Garrwa people, in particular 'Ellen' and 'Tina', for their assistance with transcription and permission to use their conversations for this project.

\section{ENDNOTES}

In addition to the usual CA transcription conventions, we use the following in the extracts:

$\begin{array}{ll}f t & \text { free translation line } \\ \text { glo } & \text { gloss line } \\ ; & \text { slight terminal rise in pitch } \\ ; & \text { slight terminal fall in pitch } \\ i & \text { medium terminal rise in pitch } \\ \text { LOC } & \text { locative } \\ \text { 3sg } & \text { third person singular } \\ \text { 3du } & \text { third person dual } \\ \text { NA } & \text { particle (meaning unclear) }\end{array}$

Ellen and Tina are pseudonyms.

\section{REFERENCES}

Egbert, M. 1997. 'Schisming: The collaborative transformation from a single conversation to multiple conversations'. Research on Language and Social Interaction 30 (1): 1-51.

Gardner, R. 1995. 'On Some Uses of the Conversational Token $m m$ '. PhD thesis, Melbourne: The University of Melbourne. 
Hayashi, J. 1988. 'Simultaneous talk - from the perspective of floor management of English and Japanese speakers'. World Englishes 7: 269-288.

Jefferson, G. 1983. 'Two explorations of the organization of overlapping talk in conversation: Notes on some orderliness in overlap onset'. Tilburg Papers in Language and Literature 28: 11-38.

Maschler, Y. 2003. 'The discourse marker nu: Israeli Hebrew impatience in interaction'. Text 23 (1): 89-128.

Moerman, M. 1988. Talking Culture: Ethnography and Conversation Analysis. Pennsylvania: University of Pennsylvania Press.

Reisman, K. 1974. 'Contrapuntal conversations in an Antiguan village'. In Explorations in the Ethnography of Epeaking, edited by Bauman, R.; Sherzer, J. Cambridge: Cambridge University Press.

Sacks, H.; Schegloff, E.; Jefferson, G. 1974. 'A simplest systematics for the organization of turn-taking for conversation'. Language 50: 696-735.

Schegloff, E. 1968. 'Sequencing in conversational openings'. American Anthropologist 70: 1075-1095.

Schegloff, E. 2000. 'Overlapping talk and the organization of turn-taking for conversation'. Language in Society 29: 1-63.

Schegloff, E. 2002. 'Accounts of conduct in interaction: Interruption, overlap and turn-taking'. In Handbook of Sociological Theory, edited by Turner, J. H. New York: Plenum.

Sidnell, J. 2001. 'Conversational turn-taking in a Caribbean English Creole'. Journal of Pragmatics 33: 1263-1290.

Tanaka, H. 1999. Turn-Taking in Japanese Conversation: A Study in Grammar and Interaction. Philadelphia: John Benjamins.

Walsh, M. 1995. 'Interactional styles in the courtroom: An example from northern Australia'. In Language and the Law, edited by Gibbons, J. London: Longman.

Cite this article as: Gardner, Rod; Mushin, Ilana. 2007. 'Post-start-up overlap and disattentiveness in talk in a Garrwa community'. Australian Review of Applied Linguistics (special thematic issue Language as Action: Australian Studies in Conversation Analysis, edited by Rendle-Short, Johanna; Nevile, Maurice). 30 (3): pp. 35.1-35.14. DOI: 10.2104/aral0735. 